Binghamton University

The Open Repository @ Binghamton (The ORB)

Fall 2016

\title{
Bringing the 21st-Century Governance Paradigm to Public Affairs Education: Reimagining How We Teach What We Teach
}

Nadia Rubaii

Binghamton University--SUNY, nadia.rubaii@binghamton.edu

Follow this and additional works at: https://orb.binghamton.edu/public_admin_fac

Part of the Public Administration Commons

\section{Recommended Citation}

Rubaii, Nadia, "Bringing the 21st-Century Governance Paradigm to Public Affairs Education: Reimagining How We Teach What We Teach" (2016). Public Administration Faculty Scholarship. 9.

https://orb.binghamton.edu/public_admin_fac/9

This Article is brought to you for free and open access by the Public Administration at The Open Repository @ Binghamton (The ORB). It has been accepted for inclusion in Public Administration Faculty Scholarship by an authorized administrator of The Open Repository @ Binghamton (The ORB). For more information, please contact ORB@binghamton.edu. 


\title{
Bringing the 21 st-Century Governance Paradigm to Public Affairs Education: Reimagining How We Teach What We Teach
}

\author{
Nadia Rubaii \\ Binghamton University, State University of New York
}

\begin{abstract}
Effective governance in the 21st-century demands a different set of competencies than prior generations, with greater emphasis on collaborative leadership, global intercultural competence, and the ability to respond nimbly to rapidly changing circumstances. Many public affairs programs have changed curriculum content to place greater emphasis on these topics. Given the extent to which such changes are altering how public issues are defined, how policies are adopted, and how programs and services are delivered as much as what those problems, policies, and programs are, then how we teach is arguably as important as what we teach. This article argues that current and future public administrators will be better prepared to work effectively across international and intercultural differences, respond to uncertainties and change, and transform traditional hierarchical silos of government bureaucracies into collaborative shared-power networks if faculty and programs model those forms of decision making and inclusion.
\end{abstract}

\section{KEYWORDS}

Pedagogy, competencies, collaboration, intercultural competence

Numerous political, social, economic, and technological changes that characterize the 21 st century are redefining public administration and public policy. ${ }^{1}$ There is widespread agreement that graduates of Master of Public Administration (MPA) and Master of Public Policy (MPP) programs need to understand, not only traditional institutions and processes of government, but more importantly a broader and more diverse array of organizations, roles, and processes involved in governance. They need skills in facilitation and collaborative leadership because they will not be able to rely solely on formal authority to get things done. They need the capacity to work across horizontal networks - which span jurisdictions, levels of government, sectors, and professionsmore so than within vertical hierarchies. They need the capacity to utilize rapidly changing technologies, including those associated with social media, and to respond nimbly and adeptly to uncertainty and change. And they must be competent and able to leverage diversity in all its forms, including on a global scale.

Much attention is accorded to how the curriculum in professional public affairs programs must change in response to these new demands. Scholars from a variety of disciplines and spanning all regions of the world have 
identified new knowledge and skills for effective governance (see, e.g., Abonyi \& Van Slyke, 2010; Farazmand, 2009; Kahler \& Lake, 2003; Kettl, 2000; Kim, 2008; Mohanty, 2014). In response, MPA and MPP programs are altering the content of their long-standing curricula, restructuring what courses are required, and/or developing new areas of specialization to address the new topics and content required. Considerably less attention has been given to the changes in instructional tools and techniques - the pedagogies that might be demanded to achieve the desired goals. ${ }^{2}$ Given that so much of the change demanded of public affairs professionals relates to process, focusing on curriculum content without simultaneously overhauling pedagogy may do our students a disservice. Specifically, espousing the virtues of shared power relations and warning of the inevitable need to surrender control to collaborative processes while simultaneously clinging to norms of faculty control within the classroom setting limits the abilities of students to experience rather than simply learn about these changes. This article makes the case that it is time for public administration and public policy programs to welcome the governance paradigm as the guiding model for pedagogical change and innovation.

\section{DEMANDS OF THE 21ST-CENTURY CONTEXT}

Many changes to which public affairs professionals must now respond can be attributed in some way to the forces of globalization. Globalization is a ubiquitous topic in public affairs in both academic and practitioner settings. Kettl (2000) notes that "in the early 1990s, the term was little used. By 2000, no speech was complete without it" (p. 490). It is seemingly on everyone's agenda, as evidenced by a review of titles and topics of articles published in leading journals in public administration and public policy, as well as conference themes and tracks of the field's national and international professional associations. Political debates on the full spectrum of policy issues, and their associated media coverage, also provide evidence of the omnipresence of globalization.
Globalization-which Thomas Friedman (1999) famously described as "the inexorable integration of markets, nation-states and technologies to a degree never witnessed before-in a way enabling individuals, corporations and nation-states to reach around the world farther, faster, deeper and cheaper than ever before" (pp. 7-8)-is much more than an economic phenomenon. It has political, military, legal, social, cultural, linguistic, environmental, and technological causes and consequences as well (Kahler \& Lake, 2003; Kettl, 2000; Mohanty, 2014). Depending on where one looks and what metrics are used, globalization can be seen to have equalizing effects within and across nations, what Friedman $(1999,2005)$ refers to as a "flatter world" with a more level playing field. Alternatively, globalization can be shown to exacerbate inequities according to what Florida (2002, 2005a, 2005b) calls a more "spikey world," in which some locations attract the most talented and creative professionals who then take them to great peaks of economic advantage and other communities are left behind in the valleys. Or perhaps the result is neither flat nor spikey but more "clustered and rough" and regionally oriented (Feiock, Moon, \& Park, 2008, p. 33). Regardless, globalization is having an influence on governance.

Globalization and international interdependencies have the potential to reduce corruption, support democracy, promote professionalism, and build capacity for sustainable development, thereby advancing the values of transparency, accountability, and ethics and ultimately promoting greater trust, legitimacy, and institutional capacity (Farazmand, 2009, p. 1012). In addition, international markets may force states to put on "golden straightjackets" (Friedman, 1999 , pp. 87-88) and adopt a prescribed set of neoliberal policies to open their economics, which includes limiting the role of government in the economy and eliminating restrictions on private investment (Kahler \& Lake, 2003). In so doing, states may effectively eliminate their ability to be responsive to the particular needs 
of their societies. It is in this context that we begin to see the challenges of globalization for governance. The ability of public affairs professionals to realize the positive consequences of globalization and to minimize the negative effects will be a function of their ability to work within the new environment of decision-making and service delivery.

Globalization influences (1) the sites of governance with simultaneous and competing pressures for both greater centralization or dispersal, (2) the degree to which governance is responsive and democratically accountability to those who are governed, and (3) the extent to which governments are forced to conform to market models or allowed to maintain both autonomy and welfare-state policies to respond to societal needs (Kahler \& Lake, 2003). The role of nation-states in a more globally interdependent world is changing. Power is shifting away from national governments in all directions; it is flowing up to international entities, devolving down to subnational units, and shifting out to private and nongovernmental organizations (Kahler \& Lake, 2003). At the most basic level, the terminology and focus of public administration has transitioned from government to governance, reflecting that power is shared across sectors, levels, and agencies. Government has been replaced by or, more accurately, has expanded to include governance.

Governance includes all "processes and institutions, both formal and informal" associated with accomplishing collective action (Keohane \& Nye, 2000, p. 12). Getting things done requires more than laws enacted by national governments and services delivered by government bureaucrats; it requires collaboration across levels and sectors and borders (Kettl, 2000). Policy and program implementation that was already complex in traditional governmental models, as described in Pressman and Wildavsky's (1973) classic account, is now even more complex and extended through contracting, reinvention, and devolution (Kettl, 2000).

The market focus of globalization has also shaped changing theories in public administra- tion, contributing to the shift from a traditional model to New Public Management (NPM) and ushering in a wave of reforms in public administration in the final decades of the 20th century and into the 21 st century. The reforms were initiated in industrialized economies in response to pressure to reduce taxation and spending while maintaining public service, and they accomplished this through the use of more market tools to increase efficiency. New Public Management approaches in developed countries have been touted as a means to improve the quality of services, reduce costs and waste, and improve efficiency. In the words of Lester Salamon (2005), governments have been "reinvented, downsized, privatized, devolved, decentralized, deregulated, delayered, subjected to performance measurement, and contracted out, all in an effort to improve public sector performance" (p. 7).

Developing countries have been slower to adopt such policies and sometimes do so less by choice than in response to globalization pressures to ensure international competitiveness of their economies (Chittoo, Ramphul, \& Nowbutsing, 2009). In many developing countries, NPM-style reforms are attempted at the insistence of international lending organizations as a condition of receiving aid, investment, and/or loans. Some have called for an end to NPM in developing countries based on the recognition that such reforms are flawed and inappropriate for export to developing countries (Manning, 2001). NPM is often presented in terms of flexibility, performance, resultsoriented management, and the decentralization of control, but it is also predicated on a transition to market models from a bureaucratic model with established institutions, controls, and professionalism in place. Implementing NPM in the absence of those preconditions simply opens the door for failure and corruption.

Despite evidence of failure in many developing countries of NPM and other reforms initiated in Washington, DC, international donor agencies such as the International Monetary Fund (IMF) and World Bank continue to promote these types of reforms (Chittoo et al., 2009). At the 
same time, there is recognition of the need to augment such reforms with attention to institutions - that is, "the rules that shape the behaviors of individuals and organizations"as an essential component of effective reform to reduce poverty and promote more sustainable and shared economic growth (Burki \& Perry, 1998 , p. 2). In this way, globalization has both spread public administration theory more widely and challenged its relevance and universal applicability.

Globalization is transforming business and production in ways that demand new roles for government, specifically in terms of policy liberalization to reduce import, export, and investment barriers; to facilitate technological change and innovation; to invest in technologies that increase the mobility and smooth flow of capital; and to support vertical and horizontal networks essential in an environment of increased competition (Abonyi \& Van Slyke, 2010). A 'traditional 'neoliberal' approach views the legitimate role of government as providing the conditions for a stable macroeconomy with clear rules of the game, such as property rights, and enforcing regulations to achieve economic stability" (Abonyi \&Van Slyke, 2010, p. s36). It also envisions a role for government in providing for national security, education, social protection, infrastructure, and health and in supporting selective technologies and industries. Globalization of production changes all of this; government needs instead to help more with capacity building so that smaller and medium-sized enterprises acquire the necessary skills (Abonyi \& Van Slyke, 2010).

In this environment, even the most economically powerful nations lack the capacity to act unilaterally. With economies around the globe linked, the consequences of a financial crisis in one location are quickly felt continents away. Globalization most obviously threatens the sovereignty of nations that have limited resources and are thus dependent on IMF and World Bank loans and obliged to comply with their terms. It also limits the sovereignty of economic powerhouses like the United States and China. Even the United States, as the world's only superpower, is unable to act alone to respond to global crisis (Kettl, 2000). In addition to the interconnected financial markets that limit national autonomy, no nation is well positioned to address problems of environmental and ecological protection, acts of terrorism by nonstate actors, or the spread of infectious diseases.

In this context, the key issue is not what policies governments should or should not enact in response to globalization, but to what extent government institutions have the capacity to work in a networked environment and to facilitate, participate in, and contribute to dialogues to generate those policy outcomes (Abonyi \& Van Slyke, 2010). Traditional administrative theory, including Wilson's (1887) classic paper and the Weberian notions of bureaucracy, provide a plethora of guidance for vertical relationships in government. More recent scholars (e.g., Milward \& Provan, 1998) have focused on horizontal relationships associated with networks. Networks involve less formal hierarchical authority based solely on position and rely more on interagency, intergovernmental, and intersectoral cooperation and collaboration. Governance demands collaboration with nongovernmental entities in the private sector and NGOs to shape policy and deliver services. Globalization redefines the role of governments and highlights the need for governance. Effective governance "requires linking versus commanding, convincing versus controlling, and enabling and partnering versus doing" (Abonyi \& Van Slyke, 2010, p. s33).

In a context characterized by "rapid change, globalization, hyper-competition and hyperuncertainty" (Farazmand, 2009, p. 1007), traditional decision making based on standard operating procedures are less useful and public administrators need to be more nimble. Just as globalization has demanded a new governance paradigm, the challenges of effective governance have implications for the programs that prepare public affairs professionals (Kettl, 2000). The implications relate to both what is taught and how it is taught. 


\section{IMPLICATIONS FOR WHAT TO TEACH}

Several scholars have extended their research on the governance implications of globalization to suggest what needs to be taught in public administration and public policy programs to prepare students for the challenges they will face as public administrators. Cain and Stier (2010), for example, portray these needs in terms of "building a new generation of leaders and workers with international experience, a global perspective, and the skills to match." Others describe the new environment as a "shared-power world" (Crosby \& Bryson, 2005) that demands a more collaborative leader and more inclusive public manager who "facilitates the practice of democracy by creating new opportunities for people with different ways of knowing public problems to work together in a collaborative space to solve problems" (Feldman, Khademian, Ingram, \& Schneider, 2006, p. 93).

An obvious implication of globalization for public affairs education is the need to prepare for public administration that incorporates greater international awareness. Internationalization can and does take many forms. Programs can promote international faculty exchanges, recruit more international students, develop courses or areas of specialization focused on international or comparative perspectives, and expand the content of required courses to include readings from around the world and assignments with an international focus (Devereux \& Dunning, 2001; Murphy \& Meyer, 2012).

Among the most commonly suggested knowledge, skills, and abilities needed within the governance paradigm are those related to working in an environment that is less hierarchical and has greater uncertainties and complexities than the public administration environment of prior generations (Kettl, 2000). "Traditional administrative capacities ... are not good enough. ... There is a need to retool in both theory and practice, ... to develop new sets of knowledge, skills, cultures and designs that are nonlinear and surprise-management-oriented in organization” (Farazmand, 2009, pp. 1007-1008). Preparing students to work within the narrow confines of traditional government personnel systems that were adopted to minimize political influence, for example, will not serve them well in an environment that requires indirect government management skills (Kettl, 2000).

As recently as 2005, Salamon (2005, p. 13) chided public affairs education for lacking sufficient integration of the nonprofit sector, for focusing too much on "public" as government, and for continuing to prepare bureaucrats when we need more "professional citizens." Education of the professional citizen would place less emphasis on preparation to work in a particular sector or type of organization and more emphasis on the ability to identify, analyze, devise solutions, and implement actions to alleviate public problems; and it would include nonprofit and public managers in the same classes and programs. The proposed paradigm of public affairs education and public problem solving would emphasize tools rather than rules, networks in place of hierarchies, collaboration in lieu of competition, and negotiation instead of command and control (Salamon, 2005).

In addition to broadening the public administration curriculum to governance rather than simply government, a transition already well under way in many universities and programs, there are calls to prepare future public administrators with more knowledge of ideas traditionally associated with other disciplines, such as economics, international relations, or computer science. For example, Abonyi and Van Slyke (2010) advise that public administrators increasingly need to understand the role of global value chains in production and be able to facilitate value chain-related trade, invest in logistics systems, strengthen enterprise clusters via horizontal and vertical linkages, help local suppliers acquire skills through training, and mediate risks associated with globalized production. These are concepts more likely to be 
addressed in economic or international business programs than in public administration. As public administration programs incorporate content more traditionally associated with computer science, economics, or business curricula, it is important that public administration education maintains its unique character, which is in part related to the public service values espoused. Legitimacy and responsiveness to the public remain important. Salamon (2005) emphasizes the need to instill values-particularly the values of justice, equality, freedom, and participation-and to prepare students to deal with value trade-offs.

Abonyi and Van Slyke (2010) wisely note the importance of managing public perceptions and expectations. If government is to take a different role in relation to the private sector, it must have a public that understands this new role and sees it as legitimate. Revitalizing public service and responding to the crisis of legitimacy is a responsibility of public administration educators and public administrators (Farazmand, 2009).

To work in a networked environment involving multiple agencies and sectors, public and nonprofit administrators need the ability to establish and work as part of multistakeholder partnerships as well as a mind-set of strategic thinking, collaboration, and partnership and the ability to engage in collaborative learning and mutual adjustment (Abonyi \& Van Slyke, 2010). Public administrators also need a greater understanding of how to facilitate collective decisionmaking processes, how to foster and maintain the relationships of trust necessary for true collaboration (Cook, Hardin, \& Levi, 2007), and how to work effectively with individuals and organizations that have different cultural norms. Much attention has been given to the importance of soft skills, including perhaps most notably the need for emotional intelligence (Mastracci, Newman, \& Guy, 2010; VigodaGadot \& Meisler, 2010), in an environment in which public administrators cannot rely on their formal positional authority and the power of government to impose their will on others.

\section{IMPLICATIONS FOR HOW TO TEACH}

When considering how to prepare students for their future roles in a governance system so drastically altered by the forces of globalization, focusing on what we teach is necessary but not sufficient. We must do more than talk about the importance of international contexts, expand course topics beyond government to include nonprofit organizations, shift the focus from vertical hierarchies to horizontal networks, increase the use of new technologies, or add economics content to our programs. To the extent that globalization is changing not only what public administrators do in their jobs, but also how they do their jobs, the teaching of public administration must do the same. Recognizing the failures of traditional approaches to teaching public administration students and training public affairs professionals, O'Leary, Bingham, and Choi (2010) caution that "conditions within the field require those of us involved in training the next and current generations of public managers to deeply consider what we teach, why we teach, and how we bring these new topics to the classroom," and they acknowledge that this is a "tall charge" (p. 585).

In keeping with demands for greater accountability to stakeholders in higher education, the definition, measurement, and assessment of competencies are the cornerstone of the international accreditation standards of the Network of Schools of Public Policy, Affairs, and Administration (NASPAA) for master's-level programs. Competencies refer to what students know and can do. In that sense they require basic knowledge (acquired through reading, listening, and/or watching) and skill (acquired through doing). Mastery of competencies requires practice. No great musician, athlete, or public speaker becomes great by merely learning about her craft; many hours of practice and honing of skills through trial and error are required. Providing students the opportunity to practice essential skills of networking, collaboration, participatory decision making, and inclusion of diversity requires a rethinking and restructuring of pedagogies. 
Conventionally, students receive information from the professor in the form of a lecture and are expected to internalize the information through memorization. Within professional disciplines, this method often fails to capture the attention and interest of midcareer students and, more importantly, fails to instill the necessary problem-solving competencies. The limitations of the traditional lecture method are well documented and many professors and programs of public administration have adopted more engaged pedagogies and have shared their experiences through published research (see, e.g., Eikenberry, 2012; Feldman et al., 2006; O'Leary et al., 2010). The ideas presented here take their notion of engagement even further, advocating that public affairs educators model the types of changes and skills that globalization demands of public administrators, essentially applying the governance paradigm to our pedagogy and practicing what we preach.

This article recommends pedagogical changes in three broad areas related to the complexity of decisions, appreciation of diversity, and shared governance via collaboration. I select these areas, not because they represent an exhaustive list of the pedagogical changes that could be used to model a governance paradigm, but rather because they illustrate the type and scope of pedagogical changes possible. The term pedagogy here refers not only to an individual instructor's classroom approach but also more broadly to general program design. Some of the pedagogical changes suggested represent an entirely new approach, while others are merely variations on instructional tools already widely in use.

\section{Pedagogies to Prepare Students for Complexity}

The case methodology, problem-based learning, and simulations are examples of pedagogical strategies that allow students to be more active participants in learning. The case methodology has a long history in the fields of medicine and law and has grown in popularity in public administration. Cases challenge learners with problems set in complex, real-world situations by describing a real situation and illustrating the complexity and interconnectedness of factors that might otherwise appear simple when considered in isolation. Working individually or in groups, students must analyze and take ownership of the problem(s); frame them in the context of the course material and corresponding literature, relevant theories, and professional values; and evaluate the varied alternatives for how to respond. The use of cases within public affairs education has become even more valuable as the practice of public management in government agencies has shifted from topdown bureaucracy and control using traditional PODSCORB management techniques (i.e., planning, organizing, directing, staffing, coordinating, reporting, and budgeting) to more emphasis on networks, collaboration, influence, and persuasion across multiple sectors. Whereas cases from the 1940s and 1950 s portrayed a functional view of public managers, recent cases portray managers as people who actively shape their legal mandates and use administrative systems to promote political objectives.

The case methodology is not without its critics. Social scientists fault cases for being atheoretical and, hence, lacking in intellectual rigor. Contemporary cases are also faulted for implicitly endorsing an "activist" or "heroic" view of public management, for focusing primarily on high-ranking officials as protagonists, for ignoring the role of community collaboration, and for giving minimal attention to issues of race, class, and gender (Chetkovich \& Kirp, 2001; Kenney, 2004). The case methodology is also more challenging to apply in settings for which there are few relevant published cases to choose from (Rubaii, Careaga, \& Leyva Botero, 2014).

Problem-based learning maintains the most effective aspects of the case methodology while addressing some of its criticisms. Problembased learning is a variation on the case method 
in which a current problem-rather than one that has already transpired-is the focus of study. Students, often working in groups, must determine a course of action and make recommendations (Miller-Milleson \& Mould, 2004) before knowing how events will ultimately unfold. Simulations place students in roles and allow them to act out and practice conversations and interactions.

These methods are a great improvement over the traditional lecture in that they engage students as active learners and creators of knowledge rather than relegate them to being passive recipients of ideas. These active-learning approaches, however, do have limitations that impede their ability to develop in students the skills necessary for the challenges of 21stcentury governance. The case method, simulations, and problem-based learning are often used within the confines of a single class. The focus is on the aspects of the case or problem related to the subject matter of the course, and the students who comprise the team are generally all from within a particular program. In using cases, simulations, or problems as teaching tools within the conventional silos of higher education, public administration education does little to prepare students to move beyond the traditional silos of public bureaucracies. As emphasized by many critics of traditional government institutions and processes, complex public problems in a globally interconnected world cannot be solved by individuals within a single government agency in a particular location (see, e.g., Crosby \& Bryson, 2005; Milward \& Provan, 1998; O’Leary et al., 2010; Salamon, 2005). Instead, we need public administrators who can work in teams that span multiple professions and sectors.

At a minimum, this suggests the need for multidisciplinary teams to work on cases, simulations, or problems. One can envision students from public administration working on the same case alongside, or at least periodically communicating with, students in engineering, economics, business, medicine, social work, or even art or psychology. And in so doing, they would learn the jargon, philosophical underpinnings, and unique perspectives of those different professions and disciplines. Teams might also expand beyond the confines of the university to include groups in the community such as nonprofit organizations, their clients and service recipients, neighborhood groups, ans so forth. These teams could also extend across international borders as illustrated by the partnership described by Miller-Milleson and Mould (2004).

If, as Farazmand (2009) contends, the new world order is also one of rapid change and hyper-uncertainties in which some changes "happen almost overnight with unfolding surprises and produce anxiety, uncertainty, and possible system breakdown across cultures and governance and administrative systems" (p. 1008), perhaps we also need to experiment with changing rules midway through assignments. This might happen naturally with problembased learning as new information is made available and conditions change. In the case methodology, the instructor or case author would be responsible for adding new information as the case progresses rather than providing all information to students at the onset.

The case method and problem-based learning typically utilize student groups formed at the beginning of a semester and retained for the duration of the class or at least the duration of the case. In the real world, new groups or organizations enter the scene and individuals depart after a process has begun. If these are circumstances for which students must be prepared, we may also need to experiment with changing group composition midway through the academic term or even very close to the end.

If we expect students to be able to cross boundaries and work in teams upon graduation, despite all the pressures they will face from long-standing organizational cultures to maintain the bureaucratic silos of government agencies, we must expose them to the challenges and benefits of these types of teams while they 
are still students. If we expect students to be flexible in responding to rapidly changing circumstances, we must provide them with changing circumstances so that they can develop that ability.

\section{Pedagogies to Prepare Students for Global Diversity}

Along with the capacity to work in teams that span organizations, professions, and sectors, globalization demands public administrators who appreciate cultural differences and diversity within and across countries and regions. To be effective protectors of the public interest, public administrators must be "prepared to advocate for diverse populations" (White, 2004, p. 114). If public service professionals lack cultural competence, negative consequences may result for their particular clients as well as the general public (Rice, 2007).

Globalization suggests that we must be able to recognize and utilize the best ideas regardless of where they originate. If globalization is creating a figuratively smaller and flatter world as Friedman (2005) suggests, ideas need to be able to flow in all directions, not simply from socalled developed to developing countries. This requires a level of global cultural competence that most public administrators and public administration students currently lack. In the absence of global cultural competence, great ideas may go unnoticed due to language or cultural barriers or preconceived stereotypical perceptions of their origin. To engage in effective governance, public administrators need to be internationally and domestically savvy. They should be well traveled within and outside their own countries, to the extent possible and beyond mere cultural excursions or tourism.

Internationalization of the public administration curriculum can happen in several ways. One avenue is via methods mentioned earlier, such as faculty exchanges, specialized courses, increased international student recruitment, and more diverse readings and assignments; these strategies represent a good first step. But public administration programs must go fur- ther wherever possible to promote meaningful interactions that foster greater understanding of, appreciation for, and ability to work with diversity. This may take the form of service learning (SL) in communities within the home country, structured study-abroad opportunities, or a combination in the form of international service learning (ISL).

Generally, ISL allows for an immersive international experience, which is widely recognized as effective in helping students recognize their biases, develop appreciation for different cultures and contexts, and build skills in effective intercultural communication (Cheney, 2001; Deardorff, 2006) and in helping to produce global citizens (Douglas \& Jones-Rikkers, 2001; Horn \& Fry, 2012). The fields of business (Metcalf, 2010), engineering (Borg \& Zitomer, 2008), nursing (Green, Comer, Elliot, \& Neubrander, 2011), and social work (Gammonley, Rotabi, \& Gamble, 2007) have all documented how ISL programs support the particular values, competency needs, and learning outcomes of their respective professions. In a 2013-2014 study of the nearly 300 NASPAA member programs, roughly two thirds of the 140 respondents offered study-abroad opportunities but only 1 program required study abroad and only 7 offered ISL programs (Rubaii, Appe, \& Stamp, 2015).

For programs without the resources to develop and manage ISL programs, or for students without the time or money to travel, a second avenue of internationalization involves programs' engaging in creative collaborations using technology to reach across international boundaries. We can learn much about the challenges and values of such arrangements from the experiences described by El Baradei and Newcomer (2005) and by Miller-Milleson and Mould (2004) regarding collaborations between programs at U.S. universities and those in Egypt and Kyrgyzstan, respectively.

More diverse domestic experiences are also essential. Too often students of public affairs 
interact with their fellow students, their faculty, and government officials in the agencies where they work or intern. Less frequently do they interact with the clients and populations in the community that receive government services and programs or with the nonprofit or privatesector organizations that work with government in service delivery.

In engaging students in service and promoting public service values, it is important that service-whether domestic or internationalnot be construed as charity, but rather as an opportunity to work alongside and engage in mutual learning and enhanced mutual understanding. This principle of solidarity grounded in reciprocity, mutuality, and attention to not reinforcing traditional power relationships (Baker-Boosamra, Guevara, \& Balfour, 2006) should be a cornerstone of ISL pedagogies (Appe, Rubaii, \& Stamp, 2016) and of all efforts to engage diverse communities.

Students of public administration cannot be expected to develop global cultural competencies without opportunities to interact with individuals and groups who have very different life experiences and cultural values than their own, to experience both the challenges and the rewards of such difference, and to practice how to communicate effectively and structure mutually beneficial relationships. If public administration programs do not provide these experiences for students, graduates will be ill prepared for the challenges of the global work environment.

\section{Pedagogies to Prepare Students for Shared Power Relations}

Among the most commonly cited changes in governance structures as a result of globalization are the declining role of hierarchical authority and the corresponding rise in the importance of shared power across networks, collaborative decision-making processes, and facilitation of group decision processes. These processes begin at the stage of defining public problems and setting goals, they include decisions about service delivery and implementation, and they extend to the establishment of evaluation criteria and measures. Whereas in the past, public administration education focused on teaching students to gather essential information, analyze that information, and make decisions, the pressures of globalization demand that students be prepared to facilitate group processes to reach decisions in each of these areas. What were core responsibilities of government officials are now shared responsibilities in which government officials may have influence but little formal authority.

Using a list of proposed competencies identified in a NASPAA white paper by Piskulich and Mandell (2008), Mastracci et al. (2010) identified several that relate to emotional intelligence, including those related to self-assessment, facilitation, flexibility, negotiation, sensitivity to difference, and managing relationships. Mastracci et al. advocate not only "talking the talk" in terms of incorporating the content but also "walking the walk" by incorporating new teaching styles. The authors present three pedagogical tools-drama workshops, selfassessments, and classroom assignments such as interviews (Mastracci et al., 2010, pp. 135136)_ as a means to develop competencies in recognizing, interpreting, and managing emotions in work settings. I contend that we need more substantial change than simply incorporating a few assignments within classes.

Modeling collaborative decision making and shared power may be the most challenging pedagogical change of the three examples presented in this article. It requires that faculty be willing to relinquish and share some of their authority with students in establishing objectives, delivery methods, and evaluation criteria. This might begin on a small scale with a single assignment but could conceivably extend to an entire course or even to become a guiding pedagogical principle for many courses within a program.

Learning contracts provide one means of doing this, in which individually tailored learning objectives, strategies, and evaluation criteria are 
developed by students in consultation with and ultimately the approval of the instructor (Rubaii-Barrett, 2006). Extending this concept considerably further, one can imagine a course in which there is no advance syllabus. Rather, the first class session would focus on collectively identifying course objectives and agreeing on communication and decision-making rules for group processes. The instructor's role is as facilitator, to ensure that group decisions fit within the boundaries of what is considered acceptable and appropriate for a course. Within these boundaries, students participate in shaping the course through a collaborative process in which they experience the challenges of, and practice their skills in, balancing individual and collective interests, communicating effectively and persuasively, and utilizing emotional intelligence.

In this approach, the process of decision making and interaction within the classroom does not replace but becomes as important as the course content. The pedagogical strategy of "flipped classrooms" is also useful here, allowing considerable content to be obtained outside the class setting via readings and videos or online chats that take the place of lectures and discussions, freeing class meetings for application of concepts, interactive exercises, and problem solving as a group (Holtzhausen \& Nkwana, 2014). Technology can also be a leveling and participatory device. In contrast to traditional course-management systems like Blackboard, which are "built on asynchronous, top-down and one-to-many models of communication (and power)" (Hanley, 2011, p. 11), faculty can use social media to more fully engage students, in the process helping them understand how to use these tools to engage and empower citizens and promote democratic participation (Eikenberry, 2012). Notably, the use of social media places professors in a position of having "less control over what is shared and with whom" and "this means a great deal more openness, but also a greater blurring of roles in the classroom and exposure to unforeseen difficulties and ethical dilemmas" (Eikenberry, 2012, p. 460).
With this recommendation, as with the previous two, the emphasis is on re-creating or simulating within the educational environment the conditions that public administration students will face upon graduating. This would help students to practice and hone their skills and be better prepared for the challenges of globalization.

\section{AN UNREALISTIC PROPOSAL?}

Can the governance paradigm be brought into public affairs education? Is the public administration and public policy profession ready to alter not only what is taught but also how it is taught, to better prepare students for $21 \mathrm{st}$ century governance challenges? We can anticipate some of the objections to such proposed pedagogical changes. There is certain to be some degree of resistance and a plethora of purported reasons why such changes are impractical or impossible. For example, there is the challenge of evaluating individual student work in the context of group or team activities, particularly if rules or team composition are changed midproject. On the one hand, the product may be quite good, but we may be unable to accurately assess an individual's contribution to the final product. On the other hand, the product may be of lesser quality for reasons outside the control or responsibility of a particular student. This is much like the challenge that human resource managers face in evaluating employee performance as more work is completed in teams and where outcomes depend on the actions of others outside the organization. The question is whether we want to design and select pedagogies based on ease of grading and evaluating student work or whether we want to design and select them based on their ability to prepare students for the demands of the 21 st century.

The recommendations provided above for changing how to teach public administration and public policy, and the reactions they are likely to provoke, reveal important lessons that link back to the discussions earlier in this article about the governance implications of global- 
ization. The prescribed pedagogical changes bring us full circle to some of the central questions and debates surrounding globalization in general, specifically whether it is possible to generalize its impacts across national and regional contexts or from institutional to individual levels (Burki \& Perry, 1998; Chittoo et al., 2009; Feiock et al., 2008; Florida, 2002, 2005a, 2005b; Friedman, 1999).

First is the question of whether the recommendations are equally applicable, relevant, and useful in all parts of the world. In a 2005 symposium on globalization and international approaches to public affairs education published in the Journal of Public Affairs Education, the articles collectively raise questions that "revolve around the transferability of administrative and educational practices from one nation to another" (Jennings \& White, 2005, p. 70). The question here is whether a change in pedagogy is equally important in a public administration program regardless of where in the world it is located and what types of positions its graduates pursue. If one accepts that future graduates will need new knowledge and skills to work in a more globally connected world, that traditional pedagogies do little to instill these new competencies, and that practice of skills is necessary to master them, then these new pedagogies are arguably universally applicable and necessary and might help elevate the quality of graduates of all programs.

Alternatively, if one imagines interactive studentcentered, multidiscipline problem-based pedagogies to be suitable only if students already have a certain level of maturity, experience, disciplinary expertise, and self-confidence, then programs comprised of students who lack those characteristics might be not reap the intended benefits. These pedagogical reforms might be the equivalent of local governments in developing countries being granted greater discretion and flexibility under New Public Management even though they lack essential institutional capacities to effectively exercise such discretion.
In this case, the proposed pedagogies might serve to further differentiate graduates from top programs versus all others. This would be particularly problematic if the institutional capacity for adoption of new pedagogies reinforced existing socioeconomic disparities among universities within or across countries. Or, quite possibly, like the experience in many developing countries with trying to implement NPM reforms absent prior strong institutions and systems of control, the new pedagogies might backfire and create opportunities for lower-quality instruction and less learning.

It is also quite possible that additional or alternative pedagogies other than those proposed here could be equally effective and more appropriate in certain national and cultural contexts. A real danger is the potential for accrediting bodies-within countries or regions or on an international scale-to mandate pedagogies, rather than desired results or competencies, as a condition of accreditation. This would be the academic equivalent of the IMF and World Bank requiring the adoption of NPM principles as a condition of aid, investment, or loans, and that is certainly not what I am proposing here.

Additionally, when one considers the challenges to implementing the pedagogical changes advocated in this article, one begins to appreciate the challenges of other prescribed changes in governance structures and operations. Beyond the resistance to change that is human nature in so many situations, the structure of universities and academic departments mirrors many of the traditional Weberian structures of government. Surrendering control and hierarchical authority-whether as a government official or as a professor-is not easy and is rarely welcomed. It is one thing to intellectually understand the value of collaborating with other organizations, working across networks rather than in silos, including stakeholders in decisions from the earliest stages, engaging clients in establishing evaluation criteria, and being transparent 
throughout; it is quite another to change entrenched patterns of behavior to do these things. But it is precisely because these changes are so difficult that they are so essential. One cannot expect the practice of public administration to make dramatic changes until the teaching of public administration models the necessary changes. In the spirit of the classic "practice what you preach" motto, one cannot truly expect graduates of MPA and MPP programs to make the necessary changes in response to the pressures of globalization if those programs and their faculty cannot make those changes themselves.

\section{CONCLUSION}

Globalization is a ubiquitous force in the practice of public administration. Regardless of whether it is narrowly or broadly defined or whether its positive or negative consequences are emphasized, globalization demands new ways of thinking and doing in government and governance. It is time to move beyond talking about and teaching about globalization in public affairs articles, texts, and classes. It is time to reimagine how the public affairs educational experience can more fully incorporate the tenets of the 21 st-century governance paradigm. This article is a call to faculty to commit to teaching in ways that allow students to practice and hone the skills necessary to lead in our globally interconnected world. Once we have in place a cadre of public administrators in countries throughout the world who not only understand the importance and challenges of globalization but also have observed, experienced, practiced, and mastered the skills to work in partnership and collaboration across networks, among diverse groups and individuals, and in an environment of considerable uncertainty, we will be better able to address the elusive aspects of globalization.

\section{NOTE}

1 This article builds on a series of presentations made at universities in Colombia in 2014 as part of a U.S. Fulbright Core Scholar appointment. I presented an earlier version of this article at the International Conference on Globalization and Public Administration: Pros and Cons, hosted by Dr. Babasaheb Ambedkar Marathwada University and Lokprashasanshastra Vikas Mandal in Aurangabad, India, January 16-17, 2015.

\section{REFERENCES}

Abonyi, G., \& Van Slyke, D. M. (2010, December). Governing on the edges: Globalization of production and the challenges to public administration in the twenty-first century. Public Administration Review, 70(s1), s33-s44.

Appe, S., Rubaii, N., \& Stamp, K. (2016). Global solidarity: Learning from volunteer frameworks in Peru. In J. Butcher \& C. J. Einolf (Eds.), Perspectives on volunteering: Voices from the South. Berlin, Germany: Springer, 151-170.

Baker-Boosamra, M., Guevara, J. A., \& Balfour, D. L. (2006). From service to solidarity. Journal of Public Affairs Education, 12, 479-500.

Borg, J., \& Zitomer, D. (2008). Dual-team model for international service learning in engineering: Remote solar water pumping in Guatemala. Journal of Professional Issues in Engineering Education and Practice, 134(2), 178-185.

Burki, S. J., \& Perry, G. E. (1998). Beyond the Washington consensus: Institutions matter. Washington, DC: World Bank.

Cain, C. G., \& Stier, M. (2010, February 3). Analysis: Internationally oriented executives needed. Government Executive. Retrieved from http:// www.govexec.com/oversight/2010/02/analysisinternationally-oriented-executives-needed/30797. 
Cheney, R .S. (2001). Intercultural business communication, international students, and experiential learning. Business Communication Quarterly, 64(4), 90-104.

Chetkovich, C., \& Kirp, D. (2001). Cases and controversies: How novitiates are trained to be masters of the public policy universe. Journal of Policy Analysis and Management, 20 (2), 283-314.

Chittoo, H. B., Ramphul, N., \& Nowbutsing, B. (2009). Globalization and public sector reforms in developing countries. Culture Mandala: Bulletin of the Centre for East-West Cultural and Economic Studies, 8(2), 30-51.

Cook, K. S., Hardin, R., \& Levi, M. (2007). Cooperation without trust? New York, NY: Russell Sage Foundation.

Crosby, B., \& Bryson, J. (2005). Leadership for the common good: Tackling problems in a shared-power world. San Francisco, CA: Jossey-Bass.

Deardorff, D. K. (2006). Identification and assessment of intercultural competence as a student outcome of internationalization. Journal of Studies in International Education, 10(3), 241-266.

Devereux, E. A., \& Durning, D. (2001). Going global: International activities by US schools of public policy and management to transform public affairs education. Journal of Public Affairs Education, 7(4), 241-260.

Douglas, C., \& Jones-Rikkers, C. G. (2001). Study abroad programs and American student world mindedness: An empirical analysis. Journal of Teaching in International Business, 13(1), 55-66.

Eikenberry, A. M. (2012). Social networking, learning, and civic engagement: New relationships between professors and students, public administrators and citizens. Journal of Public Affairs Education, 18(3), 449-466.

El Baradei, L., \& Newcomer, K. (2005). Partnering to improve education for public service. Journal of Public Affairs Education, 11(2), 83-94.

Farazmand, A. (2009). Building administrative capacity for the age of rapid globalization: A modest prescription for the twenty-first century. Public Administration Review, 69, 1007-1020.

Feiock, R. C., Moon, M. J., \& Park, H. J. (2008). Is the world "flat" or "spikey"? Rethinking the governance implications of globalization for economic development. Public Administration Review, 68(1), 24-35.

Feldman, M. S., Khademian, A. M., Ingram, H., \& Schneider, A. S. (2006). Ways of knowing and inclusive management practices. Public Administration Review, 66(s1), 89-99.

Florida, R. (2002). The rise of the creative class: And how it's transforming work, leisure, community, and everyday life. New York, NY: Basic Books.

Florida, R. (2005a). The flight of the creative class: New global competition for talent. New York, NY: Harper Business.

Florida, R. (2005b, October). The world is spikey: Globalization has changed the economic playing field, but hasn't leveled it. Atlantic Monthly, 48-51.

Friedman, T. L. (1999). The Lexus and the olive tree. New York, NY: Farrar, Straus and Giroux.

Friedman, T. L. (2005). The world is flat: A brief history of the twenty-first century. New York, NY: Farrar, Straus and Giroux.

Gammonley, D., Rotabi, K. S., \& Gamble, D. N. (2007). Enhancing global understanding with study abroad: Ethically grounded approaches to international learning. Journal of Teaching in Social Work, 27(3), 115-135.

Green, S. S., Comer, L., Elliot, L., \& Neubrander, J. (2011). Exploring the value of an international service-learning experience in Honduras. National Education Perspective, 32(5), 302-307. doi:10.5480/1536-5026-32.5.302.

Hanley, L. (2011). Mashing up the instruction: Teacher as bricoleur. Radical Teacher, 90(1), 9-14.

Holtzhausen, N., \& Nkwana, M. (2014, November). The use of the flipped classroom model as instructional design to enhance deep learning. Paper presented at the 7 th International Conference of Education, Research and Innovation, Seville, Spain.

Horn, A. S., \& Fry, G. W. (2012). Promoting global citizenship through study abroad: The impact of destination, program focus, and duration on the propensity for international volunteerism. Voluntas, 24, 1159-1179. 
Jennings, E. T., Jr., \& White, H. (2005). Introduction: Symposium on globalization and international approaches to public affairs education. Journal of Public Affairs Education, 11(2), 69-72.

Kahler, M., \& Lake, D. A. (Eds.). (2003). Governance in a global economy: Political authority in transition. Princeton, NJ: Princeton University Press.

Kenney, S. J. (2004). Gender, the public policy enterprise, and case teaching. Journal of Policy Analysis and Management, 23(1), 159-178.

Keohane, R. O., \& Nye, J. S. (2000). Introduction. In J. S. Nye and J. D. Donahue (Eds.), Governance in a globalizing world (pp. 1-44). Washington, DC: Brookings Institution Press.

Kettl, D. F. (1997). The global revolution in public management. Journal of Policy Analysis and Management, 16(3), 446-462.

Kettl, D. F. (2000). The transformation of governance: Globalization, devolution, and the role of government. Public Administration Review, 60(6), 488-497.

Kim, C. K. (2008). Public administration in the age of globalization. International Public Management Review, 9(1), 39-55.

Manning, N. (2001). The legacy of the new public management in developing countries. International Review of Administrative Sciences, 67, 297-312.

Mastracci, S., Newman, M., \& Guy, M. (2010). Emotional labor: Why and how to teach it. Journal of Public Affairs Education, 16(2), 123-141.

Metcalf, L. E. (2010). Creating international community service learning experiences in a capstone marketing projects course. Journal of Market Education, 32(2), 155-171. doi:10.1177/0273475309360157.

Miller-Milleson, J. L., \& Mould, D. H. (2004). Problem-based learning in nonprofit management education: Results from an educational partnership between the United States and Kyrgyzstan. Journal of Public Affairs Education, 10(3), 247-258.

Milward, H. B., \& Provan, K. G. (1998). Principles for controlling agents: The political economy of network structure. Journal of Public Administration Research and Theory, 8(2), 203-221.
Mohanty, B. (2014, September 28). Impact of globalization on public management. Indian Economist. Retrieved from http://theindianeconomist.com/ impact-globalization-public-management.

Murphy, J. P., \& Meyer, V. (2012). Going global: Strategies for study abroad at the School of Public Service, DePaul University, Chicago. Nonprofit Management and Leadership, 23, 137-151.

O'Leary, R., Bingham, L. B., \& Choi, Y. (2010). Teaching collaborative leadership: Ideas and lessons for the field. Journal of Public Affairs Education, $16(4), 565-592$.

Piskulich, M., \& Mandell, M. (2008, March). NASPAA standards 2009: Curricular competencies; NASPAA white paper. Retrieved from https://naspaaaccredi tation.files.wordpress.com/2014/04/whitepaper competencies.pdf.

Pressman, J. L., \& Wildavsky, A. (1973). Implementation: How great expectations in Washington are dashed in Oakland; Or, why it's amazing that federal programs work at all, this being a saga of the economic development administration as told by two sympathetic observers who seek to build morals on a foundation. Berkeley: University of California Press.

Rice, M. F. (2007). Promoting cultural competency in public administration and public service delivery: Utilizing self-assessment tools and performance measures. Journal of Public Affairs Education, 13(1), $41-57$.

Rodick, D. (1998). Symposium on globalization in perspective: An introduction. Journal of Economic Perspectives, 12(4), 3-8.

Rubaii, N., Appe, S., \& Stamp, K. (2015). Are we getting them out of the country? The state of studyabroad opportunities within NASPAA-member programs. Journal of Public Affairs Education, 21(2), 179-198.

Rubaii, N., Careaga, M., \& Leyva Botero, S. (2014, November). Los casos de estudio escritos por estudiantes como estrategia pedagógica para enseñar asuntos públicos: Lecciones de tres universidades colombianas. Paper presented at the Congreso de CLAD, Quito, Ecuador.

Rubaii-Barrett, N. (2006). Teaching courses on managing diversity: Using learning contracts to address challenges and model behavior. Journal of Public Affairs Education, 12(3), 361-383. 
Salamon, L. M. (2005). Training professional citizens: Getting beyond the right answer to the wrong question in public affairs education. Journal of Public Affairs Education, 11(1), 7-19.

Vigoda-Gadot, E., \& Meisler, G. (2010). Emotions in management and the management of emotions: The impact of emotional intelligence and organizational politics on public sector employees. Public Administration Review, 70(1), 72-86.

White, S. (2004). Multicultural MPA curriculum: Are we preparing culturally competency public administrators? Journal of Public Affairs Education, 10(2), 111-123.

Wilson, W. (1887). The study of administration. Political Science Quarterly, 2(2), 197-222.

\section{ABOUT THE AUTHOR}

Nadia Rubaii is associate professor of public administration in the College of Community and Public Affairs at Binghamton University, State University of New York. Her research focuses on issues of diversity and cultural competence, innovative pedagogies, and internationalization of public affairs education. 